\title{
LA COMICIDAD ESCÉNICA EN EL TEATRO BREVE CALDERONIANO: LA CASA HOLGONA, LAS CARNESTOLENDASY LA GARAPIÑA
}

\author{
Aurelio González \\ Centro de Estudios Lingüísticos y Literarios \\ El Colegio de México \\ Camino al Ajusco, 20 \\ 10740 México, D.F. México \\ agonza@colmex.mx
}

[Anuario calderoniano (ISSN: 1888-8046), 3, 2010, pp. 155-171]

El teatro breve cómico calderoniano, como bien ha dicho Evangelina Rodríguez Cuadros, «no se corresponde con una pasajera fase de arrogancia juvenil, sino, por el contrario, con la etapa de madurez (a partir de los años cuarenta del siglo XVII) y, sobre todo, con la de los años en que Calderón se centró en la producción cortesana y de autos sacramentales ${ }^{1} »$. En este sentido no hay que olvidar que el género del teatro cómico breve, por su propia esencia y por las convenciones de representación en su tiempo, implica una madurez de quienes se aventuran en él, pues requiere dominar una técnica dramática basada en la economía de medios, y manejar con habilidad un

${ }^{1}$ Rodríguez Cuadros, 2000b, p. 719. 
género que se caracteriza por la rapidez con que debe provocar su efecto básico: la risa, y tener — algo que muchas veces se olvidatambién el dominio del funcionamiento escénico que empareja los recursos del texto dramático con los elementos espectaculares (movimientos, vestuario, caracterización de personajes, actuación, baile, canción, etc.), pues es con estos que se complementa, potencia o crea el efecto cómico.

En el corpus calderoniano de teatro cómico breve «el autor hace un esfuerzo por utilizar una estética cómica acorde con la utilizada en su época, además mostrar su destreza a la hora de poner en escena una serie frenética y continuada de situaciones graciosas ${ }^{2} »$.

La risa con estas obras breves calderonianas se deriva entonces de las referencias implícitas o explícitas a actitudes, costumbre y circunstancias sociales exteriores que, al ser reconocidas por el espectador, y al ser parodiadas o criticadas visualmente en el escenario se vuelven mucho más cómicas, y de caracterizaciones, gestos, voces, vestuario y movimientos que de por sí tienen una carga de humor.

También hay que tomar en cuenta, como es bien sabido, que el entremés, o cualquiera de los otros géneros cómicos breves, no eran piezas autónomas (qué es como las leemos) sino que en la representación formaban parte de una función teatral sumamente compleja ya que implicaba una pluralidad de tonos. Esta complejidad, en la cual el entremés, el baile o la mojiganga son parte fundamental, hace que el espectáculo teatral pueda ser considerado como una fiesta y así en el espectacular y magnífico ritual que implicaba una fiesta teatral barroca, los elementos paraverbales eran tan importantes como las cualidades artísticas o específicamente literarias de la obra representada. «Estos factores son los que tienen que ver con la caracterización de los personajes, las acotaciones, la función de los actores, la ambientación de la acción representada, etc. [...] generalmente los propios autores - salvo contadas excepciones- prestaban escasa atención a estos elementos de representación, confiados al criterio de los autores teatrales que se encargaban de sus comedias ${ }^{3}$ ".

Sin embargo, no por esta falta de atención explícita podemos suponer que el dramaturgo no los tuviera en cuenta, sino que en mu-

2 Pérez de León, 2002, p. 1089.

${ }^{3}$ Ver Urzáiz Tortajada, 2002, pp. 56-57. 
chos casos estaban implícitos en la propia construcción dramática diseñada por el escritor. Si es evidente que el dramaturgo al componer una comedia, desde la misma génesis del texto piensa en la representación, con mayor razón debemos tomar en cuenta esto cuando se trata de una obra cómica breve. Así, muchos de los elementos escénicos presentes en los entremeses están sobreentendidos en los procedimientos y técnicas generales de actuación de la época, en la representación de algunos personajes por actores especializados en un tipo de papeles, en general de gracioso, y por la parodia o tratamiento satírico de costumbres o actitudes a las que se hace referencia, o a los tipos de personajes que se están recreando en escena los cuales eran conocidos tanto por el autor de compañía como por el público.

Es en este sentido que la construcción de las obras cómicas breves, complemento esencial de la comedia o el drama en la función del corral o incluso en la representación del auto sacramental [...] ofrece una nueva concepción de lo cómico, que se manifiesta especialmente en la expresión verbal (diálogos), el dinamismo y la instantaneidad (acciones), y en la pantomima (signos eminentemente verbales), de claras afinidades con formas de teatro breve procedentes de Italia (commedia dell'arte); otorga prioridad a la representación frente al texto; y constituye una forma de teatro en la que se valora específicamente el sujeto frente a la fábula, es decir, el personaje frente a la acción, al insistir de forma recurrente en todos aquellos elementos que encuentran en el sujeto humano una referencia constitutiva, y que pueden reducirse a tres fundamentales: lenguaje, situaciones y tipos, es decir, diálogos, funciones y personajes ${ }^{4}$.

Sin embargo, es conveniente matizar que esta preeminencia de la representación frente al texto de la que habla Jesús Maestro, deriva de la necesidad de construir escénicamente personajes tipo que en ocasiones deben ser hiperbólicos para que la parodia o la crítica puedan funcionar y que del amplio abanico de posibilidades de reconocimiento e identificación que tiene una costumbre o actitud social conocida el actor o el director escogen solamente algunas para la escenificación, sin que haya necesidad de que el dramaturgo las señale.

Pero esta libertad escénica no debilita la estructura dramática textual pues hay que tomar en cuenta que

\footnotetext{
${ }^{4}$ Ver Maestro, 1998, p. 525.
} 
el entremés consiguió, al menos durante su mejor época, mantener una estructura propia con partes bien definidas, todas ellas al servicio de un argumento central, en muchos casos relacionado con la burla, y se constituyó así en una obra breve que presentaba ante los receptores una historia trabada de burladores y burlados, donde quien salía burlado en la mayoría de los casos era un individuo o un conjunto de ellos que se alejaba del comportamiento social reglado ${ }^{5}$.

Los primeros editores modernos y rigurosos del teatro breve calderoniano ${ }^{6}$ han señalado que "sus 24 obras son un corpus que con garantías refleja el sistema de las obras breves del siglo XVII» (Rodríguez, Tordera, 1982, p. 20)7. En este sentido, la riqueza de la obra calderoniana ha sido básica en las reflexiones de los estudiosos más conocedores del género breve ${ }^{8}$. Por otra parte me parece bastante claro que Calderón al construir sus entremeses y mojigangas tiene presente una estructura y unos recursos escénicos que pueden potenciar efectivamente la comicidad de la obra y con ello la agudeza de la crítica o simplemente el elemento lúdico de la parodia. A continuación revisaré algunos de estos elementos cómicos escénicos en tres de estas obritas que son condensados excelentes de la técnica entremesil. Desde el punto de vista del contenido en el entremés de Calderón se distinguen como estrategias argumentales las tramas de burlas, los engaños frustrados o ficciones correctivas; el reflejo en escena de costumbres y aspectos de la vida cotidiana, y las inversiones paródicas respecto a su producción seria9.

Las obras a las que me referiré son La casa holgona y Las Carnestolendas, entremeses, y La garapiña, mojiganga. Las tres siguen el esquema típico del género, que para la época de Calderón ya ha comprobado plenamente su efectividad y que por tanto su éxito de público se debe más que a la novedad a la maestría con que las obras están compuestas. Esta revisión y análisis parten de mi experiencia en el

${ }^{5}$ Ver Lobato, 2003, p. 40.

${ }^{6}$ Ver Rodríguez y Tordera, 1982, p. 20.

7 Posterior a ésta de 1982, aparece en 1993 una edición crítica de los entremeses de Calderón debida a María Luisa Lobato.

8 Baste mencionar a Javier Huerta Calvo (1995), Agustín de la Granja (1981), Catalina Buezo (1993) y María Luisa Lobato (1989).

${ }^{9}$ Ver Rodríguez y Tordera, 1983, pp. 37-38. 
montaje con actores (tradicional y tratando de seguir dentro de lo posible convenciones de la época en cuanto a vestuario y escenografia) de las mismas y en constatar el efecto que producen ante un público actual ${ }^{10}$.

No hay que olvidar que, por lo general, este tipo de obra dramática, cuya complejidad es distinta y obedece a leyes propias

se construye en torno a dos núcleos: uno, constituido por la presencia siempre de personajes más o menos estereotipados y otro, que consiste en la creación de un mínimo conflicto escénico de carácter realista o costumbrista, que no tiene grandes sorpresas y que a menudo no tiene otro desenlace que la fiesta de música y baile con la que suele finalizar la pie$\mathrm{za}^{11}$.

En La casa holgona (publicada en Entremeses nuevos, de diversos autores. Para honesta recreación, Alcalá de Henares, 1643) el tema es la burla que hacen las mujeres de una 'casa plana' o no muy santa, de un caballero que se define como 'capigorrón', término derivado del uso de capa y gorra, atuendo típicamente estudiantil ${ }^{12}$ que implica en general como caracterización una vida despreocupada y libre. Esta caracterización ya implica un control de Calderón sobre la puesta en escena y representación, pero además en esta didascalia están implicados otros elementos. En primer lugar, ya que el caballero será la víctima de los abusos de las mujeres, su comportamiento desde el principio está marcado por una inferioridad en cuanto a astucia y habilidad con respecto a las mujeres, así desde que entra en escena debe mostrarse a los ojos del público como una víctima que no despierta piedad, pero sin saberlo él lo cual implica un comportamiento presuntuoso. La comicidad de la escena, en la primera secuencia donde dialogan Antón y Aguilita, surge entonces al establecerse un contraste entre el comportamiento y movimientos en el espacio físico y los dobles sentidos

10 Las Carnestolendas formó parte del montaje La gala del entremés (2002) y junto con La casa holgona y La garapiña del espectáculo Calderón en breve (2006). A su vez La garapiña se incluyó en El entremés dorado (2007). Los tres espectáculos fueron montados bajo mi dirección con el grupo de Teatro Experimental del Centro Asturiano (TECA) de la ciudad de México.

11 Bustos Tovar, 1996, p. 277.

${ }^{12}$ Lo que justificaría el tratamiento que le dan las mujeres de «licenciado». 
del diálogo, lleno de alusiones sexuales. Ya desde el tratamiento que le da Antón a Aguilita de "Ojitapada niña» se implica un juego entre los gestos y acciones de ésta y el tratamiento burlesco hacia el caballero que no sale bien parado de su pretendido ingenio. Indudablemente el diálogo tiene un desarrollo cómico en escena al que no es ajena la actuación y la gestualidad de los actores (falsamente recogida una y falsamente brillante el otro) dando por resultado una comicidad escénica paralela a la comicidad implícita en los diálogos.

El juego cómico se construye a partir de una imagen escénica: la de la mujer embozada, referencia a un uso habitual en la realidad, que aquí se parodia en estar la 'niña' "tapada de medio ojo». Antón buscará que la dama se descubra achacando lo encubierta a su fealdad (tuerta con boca de baúl y nariz de lomo de camello) ${ }^{13}$ insinuaciones con las que logra que «abra la tienda» y muestre los afeites, esto es que se descubra y demuestre que no es fea. Por otra parte el ser y el parecer también juegan en escena ya que si por un lado Antón dice que es flamenco, Aguilita comenta, obviamente con ironía: «Luego lo vide, en viéndole tan blanco» ${ }^{14}$, por otro Antón dice que le dieron de mamar tinta por leche. Este juego se prolonga a lo largo de todo el entremés e implica un juego de actitudes que subrayen la inconsistencia o contraste entre la realidad actoral y lo enunciado, pues si el actor fuese de piel muy blanca ¿dónde estaría la gracia? por lo que Antón funciona mejor encarnado por un actor moreno.

Una vez que entra el «licenciado» en la casa ${ }^{15}$, los juegos escénicos serán el apoyo básico de la comicidad de la burla. También las tres damas que entrarán en escena deben estar caracterizadas y el maqui-

13 No veo sostenible la interpretación de Amy Austin sobre la definición de la corporalidad, ni desde luego la existencia de una tienda o las connotaciones de pureza y virginidad del albayalde (Austin, 2006, pp. 390-391).

${ }^{14}$ Todas las citas están tomadas de la edición de Entremeses, jácaras y mojigangas de Calderón de Evangelina Rodríguez Cuadros y Antonio Tordera (1982). En adelante solamente cito entre paréntesis el número de versos.

${ }^{15}$ Mecanismo escénico estupendo por su sencillez y efectividad. En realidad es la puerta, posiblemente la central, por la que Aguilita sale del tablado y por la que se oye cantar dentro, a lo que responde el caballero y puede incluso retirarse siguiendo a Aguilita ya que los músicos salen "por una puerta y por otra», esto puede ser las dos laterales. Antón sale al tablado por la puerta central y los músicos se van al terminar la estrofa por una puerta lateral y la dama primera entraría por la otra puerta lateral encontrando a Antón en la escena. 
llaje debe recordar los afeites mencionados en el inicio del entremés y el vestuario será el que corresponde a damas más bien alegres y poco recatadas. Los movimientos para que funcione la caracterización deben mantener un ritmo y un tono natural, pues el entremés está muy alejado de un tono farsesco, la comicidad debe surgir de un cierto naturalismo en el que se establece un contraste con lo que sucede. Así, al mostrar Antón el "cierto diamantejo» la dama segunda obviamente debe poder quitárselo y esto debe ser perceptible para el espectador, pero debe ser hecho de manera que sea verosímil, con habilidad y sin alterar el ritmo escénico. La comicidad de las acciones de despojo debe ser paralela al juego verbal «desclavar-clavar» con el que quiere excusarse Antón.

La entrada de la dama tercera da lugar a un nuevo juego de palabras en voz de Antón a propósito del texto que dice esta dama, el cual debe ser acompañado de los gestos, posiblemente un tanto exagerados, de la misma:

Dama 3 El corazón me deja lastimado

el bazo herido, el hígado llagado

(vv. 118-119)

Es la última palabra es la que generará el cuento de la escaramuza de adargas que dice Antón, pero la forma en que la dama lo dice es importante para la comicidad, ya que evidentemente es una exageración burlesca la cual debe estar también presente en la gestualidad actoral. Ahora bien ¿Cómo debe decir su cuento Antón? ¿Debe subrayar el significado del mote y la empresa uniendo las palabras? El cambio es de 'es por ti llagado' a 'es por ti cagado', sólo que en este último caso no se descodifica explícitamente el resultado al decir:

Antón Porque si es esportica y Gado el mote, quedará el cifrador de bote en bote.

(vv. 127-128)

Por otra parte la reacción de las otras mujeres también debe ser significativa en la construcción de la comicidad; su risa, comentarios por lo bajo y movimientos deben contribuir a esto. Es evidente que el juego de palabras no debe escapársele al público y que la Dama $3{ }^{a}$ 
considera que lo ha dicho con gracia, pero Antón lo que pretende es señalar que sabe lo dañoso de las damas.

Finalmente la dama tercera pide que le traigan de beber y es cuando aparece nuevamente Aguilita con una bandeja o plato de bizcochos. La mecánica siguiente, bien ensayada y sincronizada, implica que el caballero trate de tomar un bizcocho y que en el momento preciso en que lo va a tomar, sea una dama la que lo tome con rapidez y habilidad, la mecánica debe repetirse hasta que se acaben los bizcochos, todo con aparente naturalidad para que efectivamente la escena tenga un efecto cómico. La misma mecánica se repetirá con la bebida, sólo que en este caso puede ser el músico, que entra en ese momento el que se adelante a Antón a tomar la copa que le corresponde. Es claro que todos estos movimientos deben ser medidos y aparentemente naturales para que resulten efectivamente cómicos.

Este juego del personaje que no logra tomar la comida o la bebida tiene una larga trayectoria en las secuencias humorísticas la cual llega hasta nuestros días, y no solamente en el teatro sino también en el cine, gracias a su eficacia para hacer reír.

La secuencia que cierra el entremés tiene una nueva alusión a lo moreno de Antón (trigo candeal y trechel) por lo que efectivamente el actor tendría que serlo para que el juego de palabras tuviera gracia.

Se puede decir que en este entremés de burlas, por un lado está una comicidad verbal que se apoya en alusiones sexuales y de otro tipo, bajo un discurso aparentemente neutro y formal y en un juego escénico, medido y sincronizado, en el cual el personaje se queda en blanco y es estafado, aunque esto no es un drama, sobre todo tomando en cuenta que la entrada final de los músicos es el único placer que recibirá aquel que pretendió a las alegres damas.

En Las Carnestolendas, aunque es otro entremés de burlas, el tono y el tratamiento escénico son diferentes, posiblemente mucho más farsesco o carnavalesco. Ahora quien será burlado es el 'vejete' que impide el gusto por el teatro de las jóvenes e implícitamente sus amores. Las Carnestolendas apareció publicado en Madrid en 1661 en Rasgos del ocio. En diferentes bailes, entremeses y loas. María Banura Badui de Zogbi considera que «Las formas de comicidad más comunes señaladas por la crítica son la verbal, la gestual, de la acción, de los personajes, metateatro y formas de extrañamiento. De esas formas, en este 
entremés la más utilizada es la comicidad verbal, aunque también están presentes las otras ${ }^{16}$ ». Sin embargo, dicha comicidad verbal, excelente por el ingenio en desviar los sentidos y en la brillantez barroca, es parcial si no se ve en la perspectiva escénica, esto es, en la enunciación con una caracterización visual plena, lo mismo en los personajes que representará el Gracioso, que en las 'máscaras' carnavalescas del final. En este sentido podemos decir que la comicidad escénica es esencial y posiblemente mayor que la verbal.

El entremés se inicia con el tablado vacío y las voces fuera del viejo y de las jóvenes. Indudablemente es un recurso escénico que capta la atención del espectador, pues crea un espacio extensivo al mismo tiempo que prepara la caracterización de los personajes, el viejo tratando de imponer su autoridad al pedir la capa y la joven Rufina dándole una respuesta descarada diciéndole que la tome él mismo.

Una vez que entran en escena las jóvenes, después que lo hace el viejo, hay una serie de diálogos de éstas en secuencia, lo cual pudiera hacer que en escena se mantuvieran juntas las tres jóvenes y dieran una sensación de grupo en oposición al viejo, con el consiguiente contraste de movimientos. La secuencia es una muy conocida referencia a las costumbres y la gastronomía carnavalesca salpicada por los comentarios irónicos y críticos del viejo sobre las mismas. Las jóvenes piden permiso para hacer una comedia (con las referencias a actrices de la realidad por parte del viejo) e introducen al galán de una de ellas el cual está identificado como 'gracioso' lo cual no deja dudas sobre el tipo de interpretación que hará, con un discurso plenamente barroco lleno de ingenio que se apoya en un lenguaje construido por juegos de palabras y referencias paródicas ingeniosas. La entrada del gracioso ya contiene una burla (la maza, trapo o cola que le ha puesto Luisa). La reclamación y secuencia de diálogos del gracioso con cada una de las jóvenes: Rufina, Luisa y María se presta a un nuevo tipo de movimientos escénicos - diferentes de los que habrían tenido las jóvenes con el viejo- que tendrían como eje al gracioso que podría seguirlas en desplazamientos por el escenario incrementando la comicidad de los diálogos.

La siguiente secuencia gira en torno la comida y la bebida y a las representaciones que hará el gracioso. La escenificación tiene que ser

162000 , p. 44. 
exagera y por tanto cómica. No en vano dice una de las jóvenes:

LUISA

Aquí tiene usasted un desayuno.

Gracioso

Poca cosa, mas basta para uno.

MARÍA

¡Ay cual zampa! ¡Jesús! ¿qué hambre es esta?

(vv. 108-110)

Evidentemente toda la escenificación de la acción de comer y beber está destinada a provocar la risa, casi se podría decir que es fin a sí misma, parodia del teatro que pedían las jóvenes y habilidad del actor que interpreta a un actor conocido - «Agora ha de remedar a Prado ${ }^{17}$ con una décima o soneto» pide la acotación-. Después vendrá un viejo, un negro con un ingenioso discurso escatológico y un alemán borracho. La escenificación implica varios elementos icónicos de utilería y una mecánica cuidada. En primer lugar ¿de donde toma el gracioso los elementos que pide la acotación para representar a los personajes: barbilla y gorra chata, mascarilla y bonete colorado, espada? Una posibilidad sería que el gracioso entrara con una alforja o bolsa y la dejara cerca de la puerta a donde volviera cada vez para caracterizarse, desde luego sería mejor que esto lo hiciera de espaldas al público para no romper la ficción y crear la sorpresa cómica, lo cual implica que los demás, mejor las jóvenes que el vejete, 'cubrieran' la escena y evitaran un tiempo muerto que afectaría la comicidad que se apoya en un ritmo ágil. Desde luego, aunque nada de esto se indica en el texto dramático, son conceptos habituales de la actuación en conjunto, así como la interacción del personaje representado en la ficción del gracioso, ya sea el negro, el viejo o el borracho, con los otros personajes del entremés. En ese sentido, la actuación y construcción de esos 'personajes' por parte del gracioso, evidentemente debe apoyarse en la comicidad visual (preparada por la exageración al comer y beber) para potenciar el propio discurso dramático, esto es, apelar a estereotipos y a la hiperbolización. De esta manera esta secuencia se vuelve central en cuanto a ligereza y comicidad entremesil. Calderón

17 Posiblemente Sebastián de Prado (1624-1685) quien hizo galanes con mucho éxito. Con Mariana Vaca en 1645, dirige a partir de 1651, la compañía de su padre, Antonio García de Prado. En 1658 competía con Alonso de Olmedo en hacer primeros galanes. Deja de actuar en 1673 . 
mismo deja la responsabilidad al actor ya que en la misma acotación de la secuencia donde el gracioso se transforma en «finflón o tudesco de la guarda» dice: «Habla lo que quisiere a lo tudesco, y bebe, y luego hace que está borracho" (v. 171). Lo que tenemos es una representación dentro de la representación que es el entremés, pero a su vez el marco referencial de la ficción entremesil es el tiempo de las Carnestolendas, que tendrá justificación en el propio desfile final carnavalesco. Se trata pues de una "estructura fractal ${ }^{18}$ 》 del espectáculo en cuanto la estructura básica del entremés, fragmentada o irregular, se repite a diferentes escalas.

Una vez que el Gracioso finge que se ha quedado dormido y el padre sale a buscar un esportillero, momento que aprovechan los jóvenes para escapar llevándose las joyas y el dinero, se inicia la última secuencia muy en el tono de mojiganga y el carnaval con el desfile de una serie de personajes estereotipados tomados del refranero de evidente carácter burlesco y difusa permanencia en la memoria (incluso en su significado), algunos de ellos hasta nuestros días como Perico de los Palotes. Serán los mismos protagonistas (el Gracioso, María, Luisa y Rufina) disfrazados, quienes los representen en tono carnavalesco, lo cual marca aún más el tono de burla hacia el vejete y justificación de la misma por su rechazo al amor de los jóvenes.

El entremés se caracteriza por una comicidad escénica que es redundante con respecto al texto dramático, sin embargo, esta redundancia es necesaria para que sea efectiva la comicidad verbal. El discurso del negro o del guardia alemán requiere de una imagen y una voz y un acento para poder alcanzar plenamente su sentido humorístico ${ }^{19}$.

La mojiganga La garapiña (editada por Hartzenbush con el título de Los flatos) indica en la fuente más antigua, un manuscrito de finales del siglo XVII, que fue compuesta para la Compañía de Antonio de Escamilla $^{20}$ y hay coincidencia en que posiblemente sería en 1678 que

18 Adde, 2002, p. 933.

19 Tan es así que la primera lectura, sin estos elementos, no provocaba risa, pero cuando quien representaba el papel caracterizó al personaje con voz y movimientos la risa del grupo fue instantánea.

${ }^{20}$ Antonio Escamilla, cuyo verdadero nombre era Antonio Vázquez. En 1645 representa con la compañía de Bartolomé Romero, en 1650 con la de Antonio García de Prado y en 1654, con su hija Manuela, con la de Pedro de la Rosa de cuya com- 
fue cuando esta compañía representó autos calderonianos en Madrid, con lo que sería una de las obras más tardíamente representadas de Calderón.

La pieza tiene gracia e interés y rebasa el desfile de figuras con tono de baile frecuente en el género de la mojiganga ${ }^{21}$ por «su agudo sentido satírico y extraordinaria dinámica escénica» ${ }^{22}$. Son varios los tópicos que son plasmados satíricamente en diversos planos, en primer lugar los personajes: doña Blasa, la dama frívola y superficial que reclama 'flatos' sin saber lo que son con tal de seguir la moda, después don Gil, galán y caballero pobre que inventará unos flatos para doña Blasa, pero que no tendrá dinero para pagarlos; en otro plano están las costumbres, en este caso la moda de beber aguas aromatizadas y por último un recurso teatral, aquí inverso pues se trata del hombre representando a una mujer.

Cada uno de estos elementos se potencia con excelentes planteamientos escénicos, en muchos casos frecuentes en el género, pero que de la mano de Calderón se vuelven especialmente brillantes. Así la caracterización de las damas se da por medio de diálogos ingeniosos de ritmo muy rápido y enumeraciones que se vuelven una retahíla brillante que debe corresponderse con movimientos exagerados. La creación del entorno de la novedad de las bebidas frías se logra por la introducción del habla paródica del italiano de Maese Coquerón dueño de la botillería con juegos de italiano macarrónico o descomposición de palabras que hacen de la Oaxaca fuente chocolatera mexicana el personaje de Joan Jaca.

La creación de la redoma de los supuestos 'flatos' funciona en cuanto es la secuencia bailada en la cual alternan cuatro damas con túnicas alegóricas con tres personajes burlescos: un negro, un moro, un borracho, cada uno de ellos tendría un acento y un habla particular, además de los movimientos risibles del borracho. Sin estos elementos escénicos la secuencia sería repetitiva y discursivamente poco gracio-

pañía se hace cargo en 1660. Hacía papeles de gracioso con gran éxito. Murió en 1695.

${ }^{21}$ No hay que olvidar que la mojiganga habitualmente se define como una obrilla dramática muy breve, para hacer reír, en que se introducen figuras ridículas y extravagantes.

${ }^{22}$ Ver Rodríguez y Tordera, 1982, p. 385. 
sa. Es claro que nuevamente será la parodia del habla del negro o del moro la que reforzará la comicidad.

Al terminar de llenar la redoma con el agua coloreada, se rompen los distintos tópicos, así el caballero inventa que le han robado un bolsillo de la faltriquera con el dinero y sale huyendo seguido por el tropel de la botillería. La escena se desplaza a casa de doña Blasa donde irrumpirán todos siguiendo a don Gil que lleva la redoma con el líquido y le dice a doña Blasa que esos son los 'flatos' con el consiguiente desconcierto de la dama.

Este es el marco, una escena llena de personajes y de movimientos donde finalmente irrumpe amenazante doña Aloja, vieja ridícula desde el momento en que es interpretada por un hombre que podemos suponer nos da una mujer voluminosa, mayor, falsamente vieja y vestida rústicamente en contraste con las alegóricas damas del desfile musical de la botillería de Coquerón. La secuencia implica una crítica que entonces se dirige a una circunstancia de la época la venta monopólica de bebidas refrescantes, sin embargo la escena puede ser igualmente cómica aunque se pierda dicho referente.

Evangelina Rodríguez nos dice que la crítica - y la comicidad diría yo- se encarna ${ }^{23}$

En otra fantástica figura, la castellana vieja doña Aloja — vieja zarrapastrosa representada por el actor Escamilla - de la mojiganga La garapi$\tilde{n}$ a, como bebida tradicional y sustentadora de un monopolio en la Villa y Corte por parte del gremio de Alojeros y Barquilleros, que acaba expulsando a las advenedizas y estomagantes bebidas exóticas (limonadas de vino, agua de canela y leche, mezclas de chocolate, etc.) parodia o sarcasmo de esos pseudo mitos nacionalistas.

La mojiganga concluye con un baile general de pandorga, baile popular que contrasta con el baile cuyos pasos «cruzados» interpretan las damas con alegorías de bebidas en sus túnicas coloridas cuando llenan la redoma de los supuestos flatos para doña Blasa.

Es claro que la comicidad escénica establecida en los movimientos y expresiones del negro, el moro, y el borracho culminan con la apa-

${ }^{23}$ Rodríguez Cuadros, 2000a, pp. 274-275. 
rición de doña Aloja cuya caracterización, movimientos, discurso y amenazas con un bastón (a fin de cuentas el texto habla de un báculo) satirizan una situación que debía tener presente el público. Sin embargo, aunque todo ese referente sea desconocido (como sucede en un montaje actual de dicha obras) la secuencia provoca la risa y el personaje construido y el actor tienen la justa dosis de exageración, para cerrar brillante y cómicamente la mojiganga. En este sentido la comicidad escénica no potencia una comicidad verbal, sino que es en lo escénico donde radica lo cómico: actor encarnando una vieja, movimientos contrastantes, caracterización rústica.

Podemos plantear que aunque el soporte del humor de muchas de las secuencias de estas obras sea el ingenio plasmado en el discurso verbal, el discurso escénico, más corpóreo y visual puede ser redundante, complementario o esencial para dicho contenido humorístico y, desde luego, la suma de los dos discursos —el dramático y el espectacular - rebasa ampliamente el efecto de uno de ellos, sobre todo si se apoya en la simple lectura.

Aunque como nos ha dicho Asensio que «El entremés constituye un género teatral intrascendente, juguete de un cuarto de hora, y no admite ambiciones estéticas ni psicología compleja, ni interpretación didáctica de la sociedad ${ }^{24}$ », eso no quiere decir que esté vacío de intenciones, ya que además, en buena medida, la risa parte de visiones críticas, ironías, elementos satíricos y parodias y por tanto de referentes que el teatro toma de la realidad y transforma en el escenario creando en muchas ocasiones un mundo al revés bastante complejo, alejado de la inversión carnavalesca bajtiniana ${ }^{25}$. Pero para que esos elementos puedan funcionar con plenitud es fundamental el ejercicio actoral, esto es una comicidad escénica que tiene tanta fuerza como el ingenio presente en el texto y por tanto de un dramaturgo que sea capaz de plantearla explícita e implícitamente y un director que sea capaz de recrearla.

El Calderón de los entremeses, jácaras y mojigangas es el mismo dramaturgo brillante y maestro de una técnica depurada de comedias y dramas. La historia de nuestro conocimiento del género en Calderón ha sido trazada de forma espléndida por Evangelina Rodríguez Cua-

24 Ver Asensio, 1970, p. 41.

${ }^{25}$ Ver Maravall, 1975, p. 314. 
dros $^{26}$ y es de justicia reconocer que nuestro autor sabía más de lo que se le ha querido conceder de ese mundo al revés o alterno que retratan sus obras cómicas breves.

${ }^{26}$ Ver Rodríguez Cuadros, 2000c. 


\section{Bibliografía}

Adde, A., "Las Carnestolendas, un buen ejemplo del arte cómico calderoniano», en Calderón 2000: homenaje a Kurt Reichenberger en su 80 cumpleaños, ed. I. Arellano, Kassel, Reichenberger, 2002, vol. I, pp. 933-944.

Asensio, E. «Introducción», en M. de Cervantes, Entremeses, ed. E. Asensio, Madrid, Castalia, 1970.

Austin, A. M., «Escenificación corporal y autorreferencialidad en el entremés La casa holgona de Pedro Calderón de la Barca», Bulletin of the Comediantes, 58-52, 2006, pp. 383-398.

Badui de Zogbi, M. B., «Riqueza de un entremés: Las Carnestolendas, de Pedro Calderón de la Barca», Revista de Literaturas Modernas, 30, 2000, pp. 4353.

Buezo, C., La mojiganga dramática. De la fiesta al teatro, Kassel, Reichenberger, 1993.

Bustos Tovar, J. de J., «La construcción del diálogo en los entremeses cervantinos», en En torno al teatro del Siglo de Oro. Actas jornadas XII-XIII. Almería, ed. J. Berbel, H. Castellón, A. Orejudo y A. Serrano, Almería, Instituto de Estudios Almerienses, 1996, pp. 277-289.

Calderón de la BArCA, P., Entremeses, jácaras y mojigangas, ed. E. Rodríguez y A. Tordera, Madrid, Castalia, 1983.

- Teatro cómico breve, ed. M. L. Lobato, Kassel, Reichenberger, 1993.

Granja, A. de la, Entremeses y mojigangas de Calderón para sus Autos Sacramentales, Granada, Universidad de Granada, 1981.

Huerta Calvo, J., El nuevo mundo de la risa. Estudios sobre el teatro breve y la comicidad en el Siglo de Oro, Palma de Mallorca, J. J. Olañeta, 1995.

Lobato, M. L., "Estudio», en A. Moreto, Loas, entremeses y bailes de Agustín Moreto, est. y ed. M. L. Lobato, Kassel, Reichenberger, 2003.

Maestro, J. G., "Cervantes y el entremés, poética de una comicidad crítica», en Con los pies en la tierra. Don Quijote en su marco geográfico e histórico. Homenaje a José M. ${ }^{a}$ Casasayas, coord. F. B. Pedraza Jiménez, R. González Cañal, Cuenca, Universidad de Castilla-La Mancha, 2008, pp. 525-536. Maravall, J. A., La cultura del Barroco, Barcelona, Ariel, 1975.

Pérez de LeÓn, V., «El carnaval imposible en los entremeses de Calderón», Calderón 2000: homenaje a Kurt Reichenberger en su 80 cumpleaños, ed. I. Arellano, Kassel, Reichenberger, 2002, vol. I, pp. 1089-1106.

Rodríguez Cuadros, E., «La risa del discreto: el teatro cómico breve de Calderón», en Velázquez y Calderón: dos genios de Europa, Madrid, Real Academia de la Historia, 2000a, pp. 249-282.

- "Teatro breve cómico», en Pedro Calderón de la Barca, Obras maestras, ed. J. Alcalá Zamora y J. M. ${ }^{a}$ Díez Borque, Madrid, Castalia, 2000b, pp. 718753. 
- «La sonrisa de Menipo: el teatro breve de Calderón ante su cuarto centenario», en Estado actual de los estudios calderonianos, ed. L. García Lorenzo, Kassel, Reichenberger / Festival de Almagro, 2000c, pp. 99-186.

- y A. Tordera, Calderón y la obra corta dramática del siglo XVII, London, Tamesis, 1983.

Urzáiz Tortajada, H., «Estudio», en L.Vélez de Guevara, Teatro breve, ed. H. Urzáiz Tortajada, Madrid / Frankfurt, Iberoamericana / Vervuert, 2002. 